\title{
Researching and Analyzing Vocabulary
}

\author{
I.S.P. Nation and Stuart Webb \\ Heinle, Cengage Learning, 2011, 355 pages
}

In the past two decades, research about learning and teaching second-language (L2) vocabulary has increased greatly, so both teachers and researchers will enjoy reading an engaging and accessible work in this area, Researching and Analyzing Vocabulary. The authors have succeeded in presenting noteworthy studies in important categories of L2 vocabulary research, including step-by-step analyses that help readers to become better consumers of research. More important, the information is presented in accessible language, allowing the book's 14 chapters to serve as a dynamic addition to the libraries of anyone with an interest in lexical research.

Both Nation and Webb have numerous publications on lexical issues. In this most recent work, however, they have written a more comprehensive book in which they explain how to research various aspects of vocabulary, offer expert analyses of existing studies, and enhance the likelihood that readers might conduct lexical research. In addition, this text was written to serve several types of readers including students engaged in research who seek to further their understanding of issues in L2 vocabulary learning and research and L2 instructors who wish to incorporate more evidence-based practices into their vocabulary classrooms. Because the content of the book is quite topic-specific, it is not intended for use as an introductory text on research design, but rather for informing readers with an interest in L2 vocabulary.

The organization of Nation and Webb's book facilitates its navigation. Readers with a pedagogical focus will be drawn to the first two sections, that is, the first seven chapters, which discuss both deliberate and incidental vocabularylearning and present several possible techniques that vocabulary teachers can implement in their classrooms and, more important, the research that has been conducted on these particular practices. The third section presents information related to corpus-based research such as making and using word lists. Finally, the fourth section presents information on assessing vocabulary knowledge. Readers with an interest in developing research knowledge will benefit from the presentation of multiple studies in all sections of the book as the authors discuss and critique notable studies related to the topic covered in each chapter. Also, researchers will benefit from the authors' guidelines for conducting inquiries, discussion of potential research studies, and suggestions for designing studies to bridge gaps in knowledge in specific areas of vocabulary acquisition. A closer examination of any chapter of the book illustrates this consistent organization; in this review, I focus on Chapter 11.

Chapter 11 is dedicated to measuring vocabulary size. Nation and Webb introduce this important topic by discussing its general value, noting that vocabulary size "is clearly a major determinant of successful language use" 
(p. 195). From this beginning, they discuss the specific questions that research into vocabulary size can answer. Research focused on learners' vocabulary production is first analyzed, followed by an account of research examining learners' knowledge of dictionary words. The authors systematically review the studies and explain any methodological weaknesses; these discussions are useful for encouraging readers' more diligent consumption of published research and researchers' design of rigorous studies of their own. Nation and Webb then provide a step-by-step procedure for designing a dictionary study and provide examples of studies that illustrate how each step can be accomplished. Another topic covered in this chapter is the creation of assessments using vocabulary-frequency lists; descriptions, although brief, illustrate the research that has been conducted, and they effectively pique the interest of readers who are intrigued by this aspect of vocabulary-testing. The discussion of vocabulary-size assessment reviews the issues identified earlier in the chapter, as well as others such as whether a computerized test should be used. Finally, Nation and Webb identify key research questions about assessment that have yet to be answered and explain how to design a vocabularysize test for nonreaders. Because each of the 14 chapters is similarly organized, readers can gain an appreciation of the wealth of knowledge contained in this volume.

Overall, Researching and Analyzing Vocabulary is an intriguing and thoughtprovoking read for both L2 vocabulary instructors and researchers. The guidelines and procedures provided are useful for inspiring readers to conduct thorough self-directed reviews and analyses of research in their particular area of interest and to inform their consideration of published opinions and research on L2 vocabulary.

\section{Liz Giltner}

\section{The Reviewer}

Liz Giltner is a third-year doctoral candidate in TESOL in the University of Central Florida in Orlando. She has taught French for the past 11 years and is interested in conducting research on corrective feedback for learners' written work. 